\title{
Síndrome de Edwards: desde el diagnóstico prenatal hasta el neonatólogo
}

\section{Edwards' syndrome: from prenatal diagnosis to the neonatologist}

\author{
María del Carmen Cabrera ${ }^{1} \odot$, Gustavo Ortiz ${ }^{1,2}$, Orlando Alfonso E. ${ }^{2}$, Rosana Esteche $^{2}$ \\ ${ }^{1}$ Instituto Radiológico Calvo. Asunción, Paraguay. \\ ${ }^{2}$ Cruz Roja Paraguaya, Hospital Reina Sofia. Asunción, Paraguay.
}

\section{RESUMEN}

El síndrome de Edwards o síndrome de trisomía 18 es un trastorno cromosómico autosómico que se caracteriza por la presencia de un cromosoma 18 extra, con rasgos clínicos distintivos. Se presenta un caso con diagnóstico prenatal basados en la ecografía morfológica obstétrica que condujeron a la realización ecocardiografía fetal donde resalta la displasia de la válvula pulmonar con doble lesión y la comunicación interventricular. Posteriormente se realiza cordocentesis para realización del cariotipo y asesoramiento genético.

Palabras claves: Síndrome de Edwards, ecografía obstétrica, ecocardiografía fetal, cardiopatía congénita, cariotipo.

\section{INTRODUCCIÓN}

El síndrome de Edwards o síndrome de trisomía 18 es un trastorno cromosómico autosómico que se caracteriza por la presencia de un cromosoma 18 extra, completo, parcial o en mosaico. La prevalencia de esta trisomía en recién nacidos se calcula entre 1 en 6.000 a 1 en 8.000, siendo la segunda alteración cromosómica autosómica en frecuencia después de la trisomía $21^{(1)}$.

\begin{abstract}
Edwards' syndrome, or trisomy 18 syndrome, is an autosomal chromosomal disorder characterized by the presence of an extra chromosome 18, with distinctive clinical features. We present a case with a prenatal diagnosis based on obstetrical morphological ultrasound that led to the performance of a fetal echocardiography with findings of a pulmonary valve dysplasia with double injury and interventricular communication. Subsequently, cordocentesis is performed for karyotyping and genetic counseling.
\end{abstract}

Key words: Edwards syndrome, obstetric ultrasound, fetal echocardiography, congenital heart disease, karyotype.

Investigaciones recientes mostraron un aumento de la prevalencia general de trisomía 18 en los últimos 20 años debido al aumento de la edad materna ${ }^{(2)}$.

Las características clínicas del síndrome de trisomía 18 son: deficiencia de crecimiento prenatal, características craneofaciales específicas, microcefalia y otras anomalías menores, malformaciones importantes, y marcado retraso psicomotor y cognitivo del desarrollo ${ }^{(3)}$.

Correspondencia: Maria del Carmen Cabrera, correo: mariancabrera14@gmail.com

Conflicto de interés: Los autores declaran no poseer conflicto de interés

Recibido: 09/03/2021 Aceptado: 10/11/2021

DOI: https://doi.org/10.31698/ped.48032021010

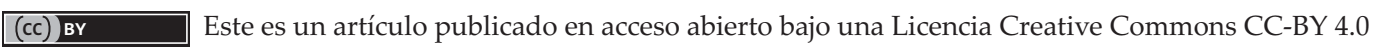


El retraso del crecimiento comienza en el período prenatal y continúa después del nacimiento, y la mayor parte del tiempo se asocia con problemas de alimentación que pueden requerir nutrición enteral ${ }^{(3)}$.

Las características craneofaciales típicas incluyen dolicocefalia, fisuras palpebrales cortas, micrognatia, anomalías externas de las orejas, y piel redundante en la parte posterior del cuello. Otros hallazgos clínicos característicos son el puño apretado con los dedos superiores dedo índice superponiendo el tercero y $5^{\circ}$ dedo superponiendo el $4^{\circ}$ que es particularmente distintiva, uñas pequeñas, pulgares subdesarrollados, esternón corto y pies de palo. La presencia de malformaciones importantes es común, y cualquier órgano y sistema puede verse afectado. Los defectos cardíacos estructurales ocurren en más del $90 \%$ de los bebés ${ }^{(3)}$.

En las últimas décadas los avances en medicina fetal y genética fueron exponenciales y actualmente se realiza el diagnóstico prenatal con precisión, lo que nos direcciona a un adecuado asesoramiento genético familiar, orientación de estudios diagnósticos específicos y control de las posibles complicaciones, pues presentan alto riesgo de pérdida fetal o mortinato ${ }^{(4)}$.

\section{CASO CLÍNICO}

Paciente de 36 años, primípara, con 28 semanas de gestación derivada para realización de ecografía fetal morfológica.

Se realiza la ecografía 2D,3D ,4D y color Doppler utilizando equipo General Electric, Voluson E 10 con transductor convexo y volumétrico.

Describimos los datos patológicos hallados en el feto, único, activo en posición cefálica.

- Crecimiento en percentil inferior a 3 , curva a controlar. Peso 771 gramos. Líquido amniótico aumentado. -Rostro: maxilar inferior disminuido de tamaño. (micrognatia) - Tórax: asimetría en cavidades cardiacas y en corte de tres vasos aumento del diámetro del tronco pulmonar. - Vejiga: irregularidades en la pared vesical. - Cordón: edema de la gelatina de Wharthon - Miembros superiores: mano cerrada con dedos superpuestos.

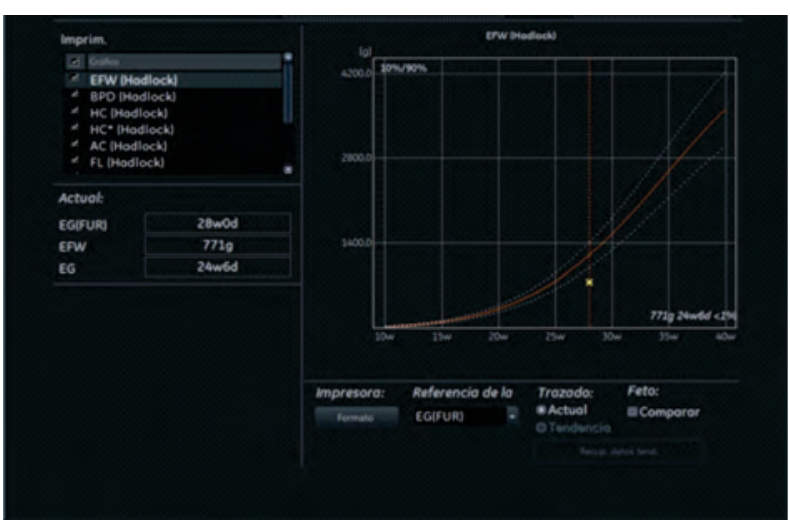

Figura 1. Retardo de crecimiento intrauterino precoz, percentil $>3$

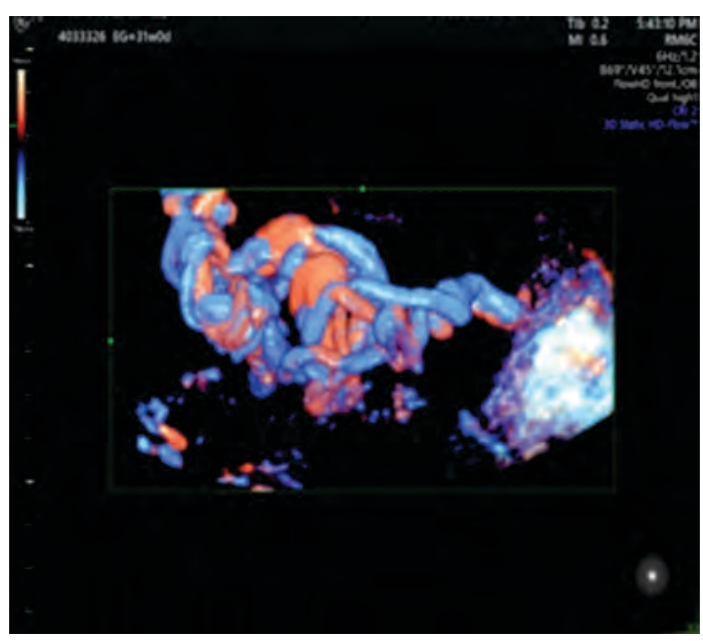

Figura 2. Edema de la gelatina de Warthon

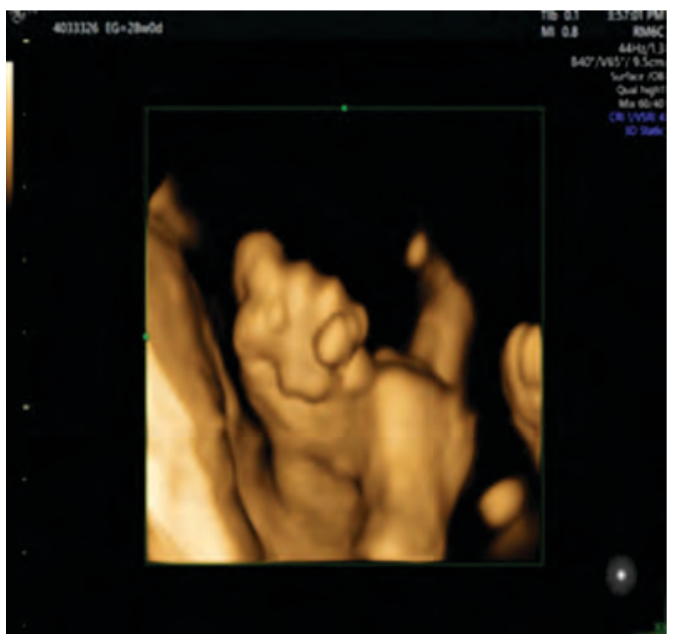

Figura 3. Dedos superpuestos 


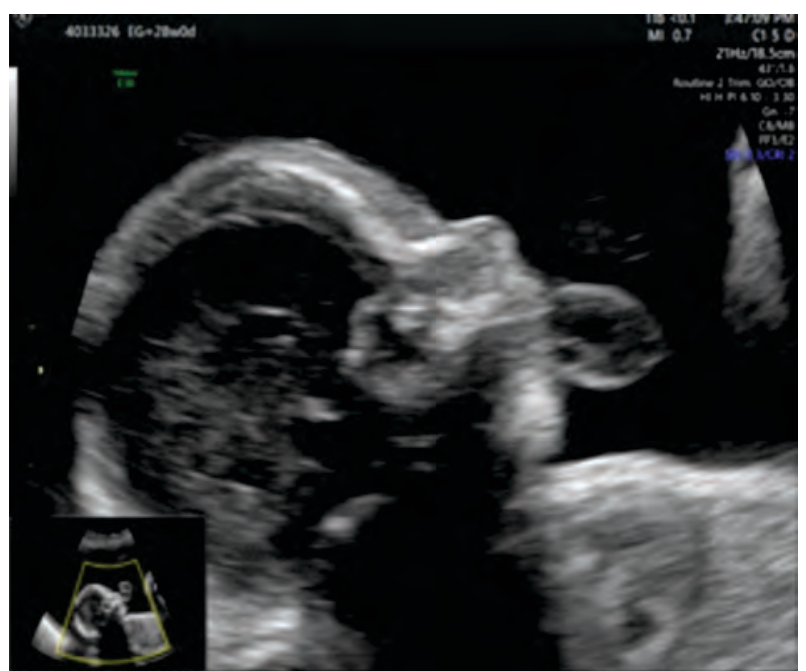

Figura 4. Micrognatia 2D

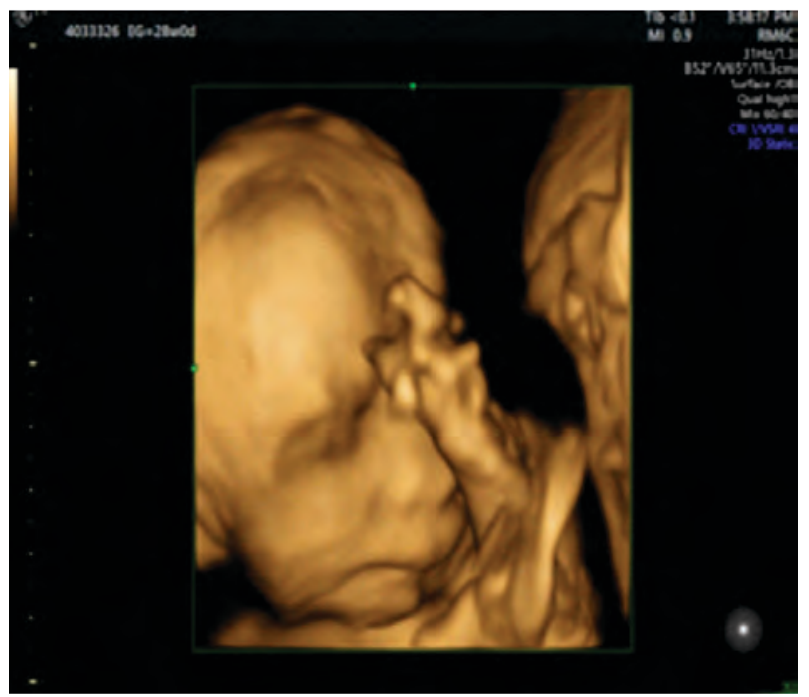

Figura 5. Micrognatia 3D

La ecocardiografía fetal: Frecuencia 162 latidos por minuto, ritmo regular, conducción $1: 1$. Comunicación interventricular subaortica. Válvula pulmonar displásica engrosada con estenosis e insuficiencia importantes. Tronco pulmonar dilatado. Aumento de cavidades derechas.

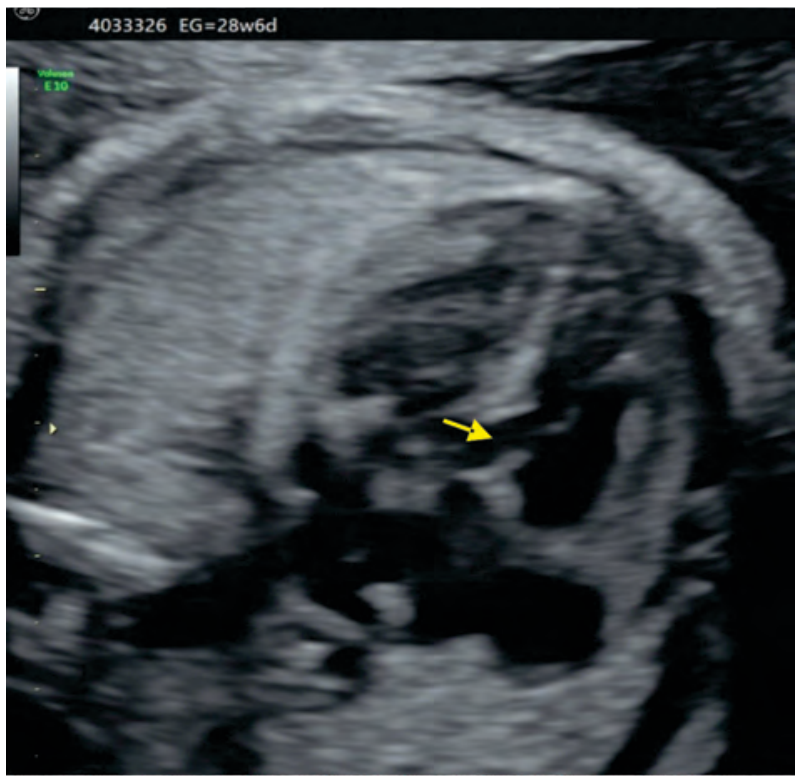

Figura 6. Imagen de 4 cámaras: Comunicación interventricular.

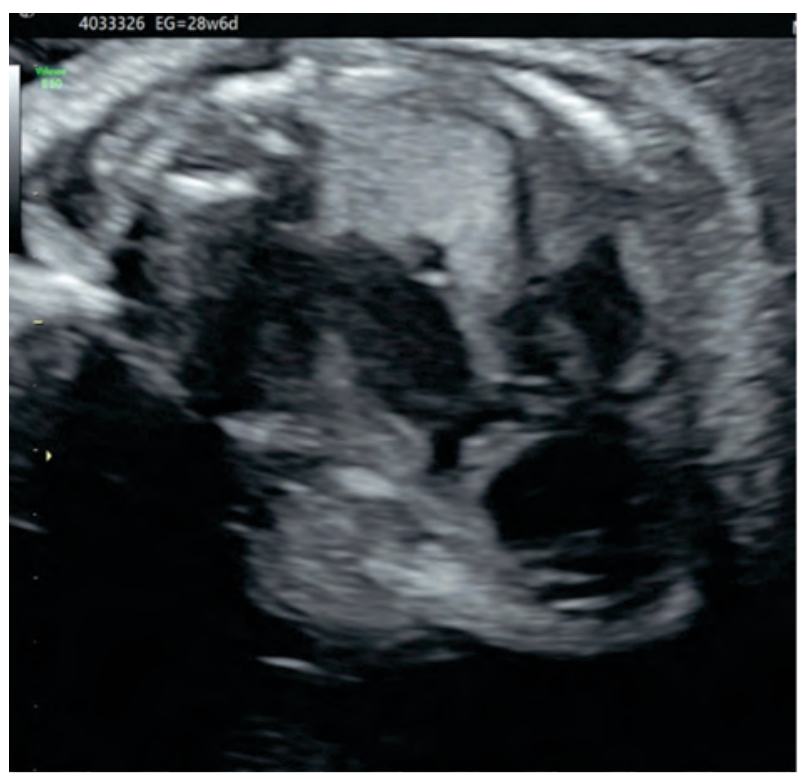

Figura 7. Imagen del tracto de salida del ventrículo derecho. Subaortica válvula pulmonar engrosada, tronco pulmonar dilatado. 
Ante estos hallazgos se indica cordocentesis para la realización de estudio cromosómico.

\section{- DATOSDE LA MUESTRA}

- Muestra: Sangre de cordón umbilical en Heparina - Motivo del Análisis: Cardiopatía, restricción del crecimiento, polihidramnios, micrognatia, dedos superpuestos.

- TÉCNICA:

- Cultivo: Cultivo de la muestra en Karyomax medium

- Coloración: Conven. con Giemsa/Identifi. Bandeo G

- RESULTADO

- Número de células analizadas: 40

- Número de cromosomas: $\quad 47$

- Fórmula Cromosómica: $\quad 47, \mathrm{XX},+18$

- DIAGNÓSTICO: En todas las metafases analizadas, a partir de linfocitos cultivados se ha obtenido una fórmula cromosómica $47, \mathrm{XX},+18$, lo que corresponde a un cariotipo femenino con trisomía del cromosoma 18 . Se adjunta imagen de una metafase señalando a los tres cromosomas 18 . Figura 8

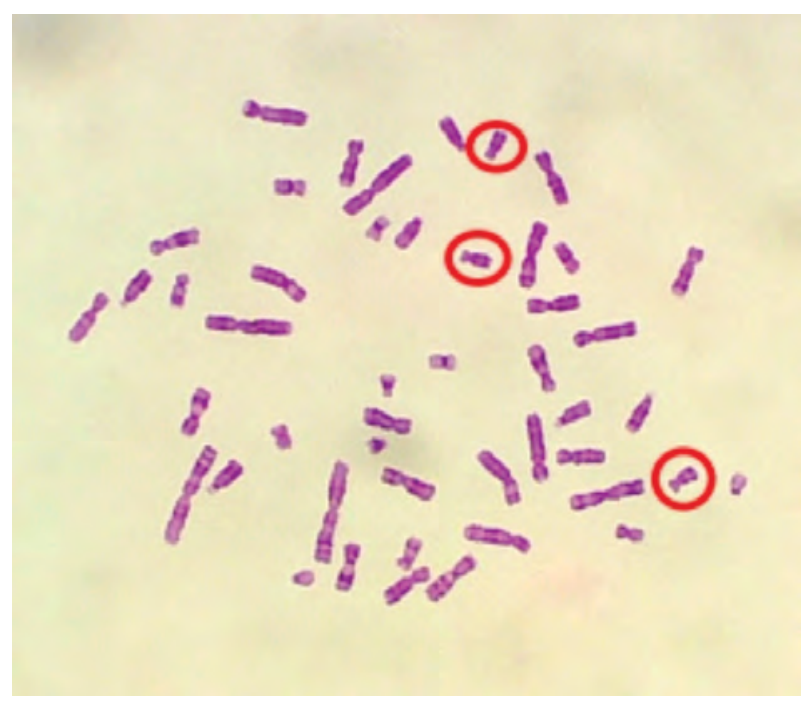

Figura 8. Metafase de tres cromosomas 18.

\section{DISCUSIÓN}

Se destaca la importancia del cribado ecográfico del primer trimestre y la realización de la ecografía obstétrica morfológica como marcador de sospecha de cromosomopatías, apuntar al diagnóstico temprano como conducta ideal, pero en este caso, la paciente recién fue referida a las 28 semanas de gestación, hecho que refleja nuestra realidad país, cuando el seguimiento prenatal se realiza en centros alejados de nuestra capital en detrimento de un diagnóstico precoz. Los hallazgos patológicos en la ecografía morfológica realizada condujeron a la realización de la ecocardiografía fetal y ambos estudios decisivos para aprobar y realizar la cordocentesis. El estudio cromosómico confirmo la sospecha de Trisomía 18.

En otros casos los marcadores séricos maternos motivan los estudios ecográficos especializados en el primer trimestre, se aclara que en este caso no fueron realizados ${ }^{(5,6)}$.

Se suma la importancia de la implementación de servicios de asesoría genética con profesionales especializados para la conformación del equipo multidisciplinario y como herramienta fundamental para los padres ${ }^{(7)}$.

Cuando se realiza el diagnóstico prenatal o neonatal de trisomía 18, el asesoramiento de la familia debe ser realista, pero no desolado y no directivo. Los padres tienen que estar preparados tanto para la probabilidad de muerte como para la posibilidad de vivir $^{(4)}$. Debido a que los padres tienen que tomar decisiones prácticas de acuerdo con sus valores respecto a la reanimación, cirugía y soporte vital, todas las opciones para el manejo del recién nacido deben explicarse, también debe responderse a la pregunta ineludible de la probabilidad de recurrencia ${ }^{(8)}$.

En el aspecto cardiovascular las diversas series muestran que entre el $80 \%$ y el $100 \%$ de los pacientes con trisomía 18 tienen defectos cardíacos estructurales congénitos ${ }^{(9)}$. La ecocardiografía fetal está indicada. Las anomalías cardíacas más comunes son las comunicaciones interventriculares e interauriculares, la persistencia del ductus $\operatorname{arterioso}^{(5,9)}$. La displasia marcada de la válvula pulmonar con doble lesión estenosis e insuficiencia con marcada dilatación del tronco pulmonar y ambas ramas como se observa en este feto es poco frecuente, debiendo realizarse el diagnóstico 
diferencial con la agenesia de la válvula pulmonar por lo que se enfatiza en la identificar la válvula pulmonar. La presencia de comunicación interventricular si es característica más frecuente el Síndrome de Edwards ${ }^{(10)}$.

La complejidad y la gravedad de la presentación clínica al nacer hacen que el manejo perinatal y neonatal de los bebés con trisomía 18 sea particularmente desafiante, controvertido y único entre múltiples síndromes de anomalía congénita. La comunicación temprana con el equipo de neonatología es fundamental para la conducta terapéutica, al respecto cabe mencionar que el

\section{REFERENCIAS}

1. Cereda A, Carey JC. The trisomy 18 syndrome. Orphanet J Rare Dis. 2012;7:81. doi: 10.1186/1750-1172-7-81

2. Irving C, Richmond S, Wren C, Longster C, Embleton ND. Changes in fetal prevalence and outcome for trisomies 13 and 18: a population-based study over 23 years. J Matern Fetal Neonatal Med. 2011; 24(1):137-41. doi: $10.3109 / 14767051003758879$

3. Baty BJ, Blackburn BL, Carey JC. Natural history of trisomy 18 and trisomy 13: I. Growth, physical assessment, medical histories, survival, and recurrence risk. Am J Med Genet. 1994; 49(2):175-88. doi: 10.1002/ajmg.1320490204

4. Carey JC. Health supervision and anticipatory guidance for children with genetic disorders (including specific recommendations for trisomy 21, trisomy 18, and neurofibromatosis I). Pediatr Clin North Am. 1992; 39(1):25-53. doi: 10.1016/s0031-3955(16)38261-x

5. Musewe NN, Alexander DJ, Teshima I, Smallhorn JF, Freedom RM. Echocardiographic evaluation of the spectrum of cardiac anomalies associated with trisomy 13 and trisomy 18. J Am Coll Cardiol. 1990; 15(3):673-7. doi: 10.1016/0735-1097(90)90644-5 consentimiento adquirido fue únicamente para la presentación de imágenes prenatales, enfatizado por los padres.

La necesidad de medicina fetal de calidad ya se encuentra incrementada, se cuenta con excelente capacidad diagnóstica y terapéutica, pero en nuestra sociedad interconectada con información globalizada el equipo multidisciplinario, obstetra, genetista, neonatólogo y especialistas pediátricos en diversas áreas tiene que conciliar respuestas al creciente nivel de exigencias según cada caso en particular.

6. Staples AJ, Robertson EF, Ranieri E, Ryall RG, Haan EA. A maternal serum screen for trisomy 18: an extension of maternal serum screening for down syndrome. Am J Hum Genet. 1991; 49(5):1025-1033.

7. Chaix MA, Andelfinger G, Khairy P. Genetic testing in congenital heart disease: A clinical approach. World J Cardiol. 2016; 8(2):180-91. doi: 10.4330/wjc.v8.i2.180

8. De Souza E, Halliday J, Chan A, Bower C, Morris JK. Recurrence risks for trisomies 13, 18, and 21. Am J Med Genet A. 2009; 149A(12):2716-22.doi : 10.1002/ajmg.a.33099

9. Van Praagh S, Truman T, Firpo A, Bano-Rodrigo A, Fried $\mathrm{R}$, McManus B, et al. Cardiac malformations in trisomy-18: a study of 41 postmortem cases. J Am Coll Cardiol. 1989; 13(7):1586-97. doi: 10.1016/0735-1097(89)90353-7

10. Balderston SM, Shaffer EM, Washington RL, Sondheimer HM. Congenital polyvalvular disease in trisomy 18: echocardiographic diagnosis. Pediatr Cardiol. 1999; 11(3):138-42. doi: 10.1007/BF02238843 